\title{
El gaucho Martín Fierro traducido al árabe: paratexto de una edición de 1956
}

\section{El gaucho Martín Fierro translated into Arabic: Paratext of an edition from 1956}

\author{
Traducción del árabe e introducción de \\ SHADI ROHANA*
}

\section{Introducción: un libro peregrino}

Recorrer, en línea recta, el pasillo con libros en lengua árabe del sótano de la biblioteca Daniel Cosío Villegas de El Colegio de México es pasear por los senderos de un jardín de curiosidades cuya existencia es inconcebible fuera del continente americano: libros de poesía de la resistencia palestina; una tesis sobre el descubrimiento de América por los fenicios; novelas de Gamal al-Ghitani dedicadas por el mismo autor "al pueblo de México"; el archivo completo de la revista literaria beirutí Al-Aadab; un diccionario árabe-español publicado en México durante la primera mitad del siglo xx; las primeras traducciones de Dostoievski al árabe; una traducción al árabe de Las huellas del islam en la literatura española de Luce López-Baralt, publicado en conjunto por la Universidad de Puerto Rico y el Centro de Estudios Otomanos y Moriscos de Túnez; ediciones olvidadas de Las mil noches y una noches y una edición crítica publicada en Leiden en 1984; libros sobre marxismo; tratados religiosos, lingüísticos y filosóficos; y libros en árabe cuya circulación fue limitada al territorio latinoamericano que se extiende desde Argentina a México.

Es el caso de una traducción al árabe del poema El gaucho Martín Fierro, del argentino José Hernández, publicada en Bue-

Recepción: 20 de noviembre de 2017. / Aceptación: 19 de febrero de 2018.

*El Colegio de México, srohana@colmex.mx 
nos Aires en 1956 por la Asociación Cultural Siria y realizada por el sirio-argentino Yauad J. Nader. El libro contiene en la primera página una dedicatoria escrita a mano con pluma. Esta nota es un indicio no sólo de cómo terminó este libro en las estanterías del sótano de la biblioteca, sino también de las redes culturales y literarias que se tejían entre migrantes de origen árabe en el Nuevo Mundo. La nota está escrita en árabe, y así puede ser traducida al español: "Para el periodista y luchador, el dueño de la revista Emir en México, el maestro Alfonso Aued. Con admiración y respeto. El traductor (Buenos Aires, 29 de junio de 1965)”.

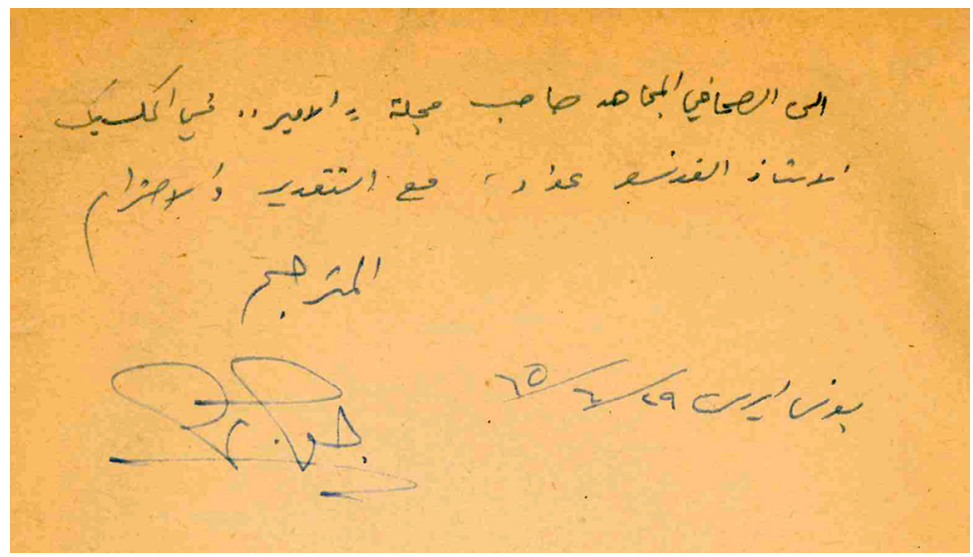

Imagen 1. Dedicatoria del traductor a Alfonso Aued.

Se trata, entonces, de don Alfonso Aued, jefe de redacción de la revista Emir. Publicada en la Ciudad de México entre 1937 y 1968, Emir contaba con colaboraciones de escritores y lectores de ascendencia árabe no sólo de México, sino también de países latinoamericanos como Argentina, Honduras, Cuba y la República Dominicana. Los números de esa revista mensual, una de las más longevas entre las comunidades del mabyar latinoamericano, ${ }^{1}$ pueden ser consultados también en la biblio-

${ }^{1}$ Mabyar: voz árabe para denominar a las comunidades de origen árabe en la 


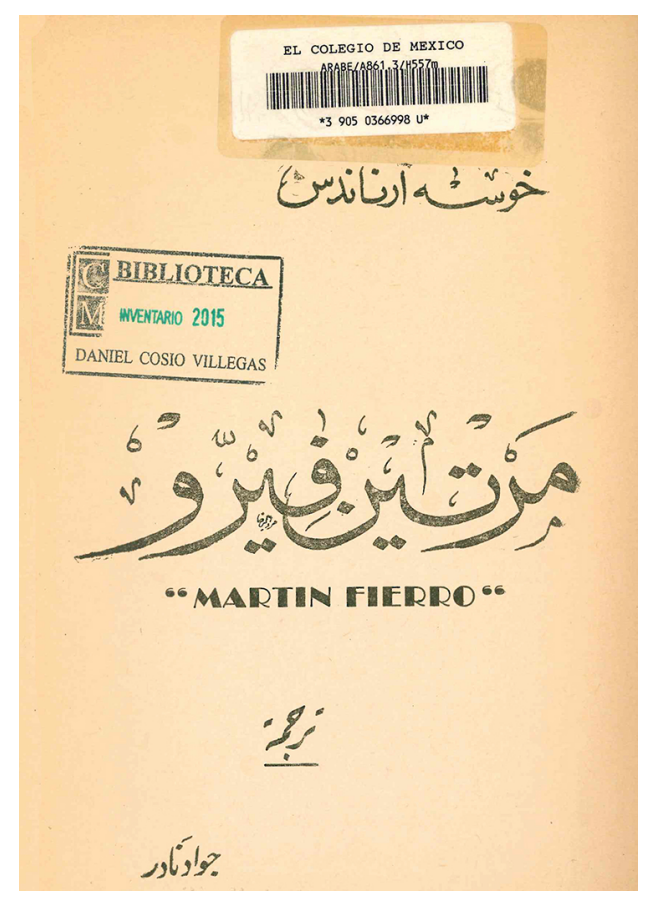

Imagen 2. El Martín Fierro en árabe (p. 3).

teca Daniel Cosío Villegas, a la que Alfonso Aued donó su biblioteca personal, que, además, incluye la edición árabe de El gaucho Martín Fierro de la que hablamos aquí.

Se presenta la traducción del árabe al español de los paratextos que acompañan esta edición de 1956; a saber: la introducción, escrita por el orientalista y arabista argentino Osvaldo Machado, y el prólogo, del traductor Yauad Nader. En éste, Nader explica sus motivos para traducir la obra, los métodos que siguió y las decisiones que tomó en el proceso de traducción del poema.

El libro incluye, además, un texto en lengua española: “Analogías entre el 'gaucho' y el ‘beduino”, escrito por Julio

diáspora. Sobre la actividad cultural y literaria entre las comunidades del mabyar latinoamericano, véase Pastor, 2014. 
Chaij - presidente de la Asociación Cultural Siria en aquel entonces-, de quien poco sabemos. Es interesante notar, sin embargo, que en el prólogo Nader se refiere a Chaij como Jalil y no como Julio, a la manera de los migrantes árabes en América Latina, que solían "devolver" sus nombres latinos al árabe o adquirir nombres españoles en su nuevo hogar. ${ }^{2}$ No se tradujo al español una breve biografía del autor del Martín Fierro, escrita en árabe, que aparece al principio del libro, pues carece de cualquier valor específico para los propósitos de este artículo por ser una reproducción de información general disponible en otras fuentes.

Antes de presentar la traducción del Martín Fierro al árabe, cabe decir algunas palabras acerca el contexto social y lingüístico en el que se efectuó, y que pueden servir como claves para la lectura de los textos de Machado y Nader.

\section{Claves para leer el Martín Fierro árabe}

Si buscamos en Google la combinación de palabras "Martín" y "Fierro" en árabe, el buscador nos remitirá a la que, aparentemente, es la única traducción del Martín Fierro a dicha lengua: la realizada por el egipcio Abd al-Salam Basha, publicada por la casa editorial Safsafa en El Cairo en 2016. Sin embargo, no es la primera ni la única. La edición de 1956 de la Asociación Cultural Siria de Buenos Aires, que consta de 318 páginas y cuyo tiraje se desconoce, es una traducción que se hizo 60 años antes.

Como mencioné, además de la traducción del poema, tanto la introducción del orientalista y arabista argentino Osvaldo Machado como el prólogo del traductor, Yauad Nader, son textos cuyo rescate, hoy, puede resultar de sumo interés para traductores latinoamericanos e investigadores de la traducción.

Osvaldo Machado es un reconocido orientalista y arabista argentino que es presentado por Nader como erudito y maes-

\footnotetext{
${ }^{2}$ Así, un Miguel es también un Mishel, y un Juan es también un Hanna. Pero, a diferencia de los pares Miguel-Mishel y Juan-Hanna, la única relación entre el nombre árabe Jalil y el español Julio es fonética; en el caso de los dos primeros, las "variantes” árabe y español se utilizan para referirse al mismo santo cristiano.
} 
tro de la lengua árabe cuyo nivel es "igual que el de nuestros grandes letrados” en esa lengua (en Hernández, 1956, p. 5). La obra de Machado abarca la filosofía y la historia árabes, y en sus publicaciones destaca una constelación de editoriales relacionadas con la cultura árabe y la actividad cultural de la comunidad del mabyar argentino. ${ }^{3}$ En su introducción, Machado agradece al traductor por "su brillante esfuerzo y valioso servicio para ambas literaturas - la argentina y la árabe- efectuados con la traducción de la vida de un héroe argentino" (en Hernández, 1956, p. 6), y compara a Martín Fierro con el poeta y caballero andante preislámico Antara ibn Shaddad al-Absi (525-608), cuya poesía formaba parte de los $M u^{\prime}$ allaqat, poemas que fueron colgados de la Kaaba en La Meca.

En cuanto a Yauad Nader, su esposa, Florinda Jazhal, narró en un programa de televisión de un canal público argentino:

Nació en Siria, en el pueblo de Bershin [en las cercanías de Homs]. Estudió en la ciudad de Trípoli, en Líbano, en la Universidad Americana. Como tenía hermanos acá en la Argentina, lo mandaron a llamar cuando era joven todavía. Acá siguió trabajando como traductor en los diarios Assalam y el Siriolibanés. Después, trabajó en la embajada de Siria por cinco años, y en los últimos años trabajó en la embajada de Libia como traductor también (Centro Islámico de la República Argentina, 2012).

Como se puede deducir de su prólogo a la traducción del Martín Fierro, Nader también fue miembro de Al-Hizb al-Suri al Qawmi al-Iytima'i (Partido Sirio Nacionalista Social, sNs), cuya actividad política y cultural fue intensa entre las comunidades del mabyar latinoamericano. Establecido por Antún Sa'adeh (1904-1949) en 1932, este partido, de carácter nacionalista y laico, buscó la unificación de la "Gran Siria” (actuales territorios de Siria, Líbano, Palestina/Israel, Jordania y la isla de Chipre) como condición para alcanzar la independencia y

${ }^{3}$ Así, por ejemplo, en el Catálogo Público de la Biblioteca Nacional Mariano Moreno de la República Argentina (http://catalogo.bn.gov.ar/F) se encuentran los siguientes títulos de Osvaldo Machado: La vida y obra de un sabio árabe: Meys-ed Din Al Firuzabadi, el de Chiraz (1935), Recuerdos y valoración de May (Buenos Aires: Assalam, 1943), La historia de los godos según Ibn Jaldún (1944), y un prólogo a la traducción española del libro canónico History of the Arabs, del historiador libanés Philip Hitti, traducido al español como Los árabes (1944). 
la autodeterminación del "pueblo sirio" y superar la fragmentación y la división de su territorio, llevados a cabo por las potencias europeas y sus agentes en la región (Sa'adeh, s.f.). ${ }^{4}$

Nader hace una alusión directa al "nacionalismo social sirio" y a su líder Sa'adeh cuando lo compara con el autor del Martín Fierro. Ambos, Sa'adeh y Hernández, dice Nader, señalaron "con valor las enfermedades y los efectos psicológicos que obstaculizan el camino de la nación [...] hacia el progreso, la excelencia y la gloria” (en Hernández, 1956, pp. 11-12).

Recordemos, en este sentido, que se trata de aquellos años marcados por el primer peronismo y justicialismo en Argentina (un país, además, que fue recorrido por Antún Sa’adeh durante su exilio latinoamericano entre 1938-1946). ${ }^{5}$ Durante esos años, el culto al gaucho y a la figura de Martín Fierro como símbolo de la nación argentina encontró domicilio en varios brazos educativos y culturales oficiales del país (Casas, 2015).

La formación del sNS se inserta en el marco del proyecto de Al Nahda árabe, del "despertar" que, desde finales del siglo XIX, busca situar a los árabes como herederos de una civilización gloriosa preotomana y como cosmopolitas modernos. Dicho proyecto, que gozó de múltiples capas y disfraces, fue contenido, y luego derrocado, por la colonización europea a finales de la Primera Guerra Mundial. Delegada por aquella precursora de la Organización de las Naciones Unidas, la llamada Sociedad de Naciones, la invasión europea a los exterritorios otomanos tomó la forma de "mandatos" para preparar a las regiones en cuestión, mediante "consejos y auxilios", a gobernarse en el futuro (Pastor, 2011).

El proyecto Al Nahda incorporó elementos discursivos que fueron comunes en el mundo colonial durante los siglos XIX y xx, principalmente la afirmación de que una nación debe despertar del largo periodo de olvido y letargo que la separa del

${ }^{4}$ El nombre del partido, que a menudo es traducido como "Partido Socialnacionalista Sirio”, junto con su simbología, han llevado a vincularlo directamente con el Partido Nazi en Alemania, algo que el sns refutaba a menudo. Sobre este debate en el contexto de la colonización europea y la política del movimiento sionista en Palestina, véase Achcar, 2013.

${ }^{5}$ Según la biografía breve de Sa'adeh que se encuentra en la página oficial del SNS (Ma qabl al-Ta'sis [Previo a la construcción], s.f.). 
antiguo esplendor glorificado e idealizado. Así, como proyecto renacentista, la intelligentsia árabe de Al Nahda adoptó la tesis de que su mundo era decadente, y se construyó una Edad de Oro imaginada que abarcaba desde el surgimiento del islam en el siglo vII hasta el comienzo del Imperio otomano y la llamada decadencia en el siglo XIV (Massad, 2007). Trasladada a la actualidad latinoamericana de finales del siglo XIX y principios del $\mathrm{Xx}$, esa necesidad de actualizar y reconstruir el pasado, como vemos en los textos de Machado y Nader, encontró un terreno fértil.

\section{La lengua del Martín Fierro árabe}

Una de las capas del proyecto Al Nahda fue el fusha, "la elocuente"; a saber, la lengua árabe escrita que hoy se conoce como "árabe estándar moderno". Esta variante, que emergió del árabe clásico, vino a "satisfacer la necesidad de tener una forma estandarizada del árabe que pueda ser expresada por la escritura" (Bin-Muqbil, 2006, p. 14). Desde finales del siglo XIX hasta hoy, el árabe estándar moderno se ha convertido en "la lengua de los medios de comunicación, sistemas de educación pública, y prácticamente todas las formas técnicas y escritas del árabe, como la de los círculos intelectuales", una suerte de lingua franca para los habitantes de los países árabes modernos (p. 14).

El surgimiento de esta variante del árabe escrito — basada en textos literarios, religiosos y gramaticales de los siglos vII al IX, que comenzaron a ser considerados como "el archivo canónico del pasado árabe” por los intelectuales de Al Nahda (Massad, 2007, p. 2) - trajo consigo normas estructurales literarias que debían seguirse en la creación literaria moderna, pues aquellos textos antiguos se convirtieron en autoridad moral y lingüística para el quehacer literario. Previsiblemente, a lo largo del siglo Xx se produjeron diversos debates acerca de cómo se debía hacer literatura, debates que no se han resuelto hasta el día de hoy.

La vieja e infinita querella acerca de la poesía en verso libre se manifiesta en el prólogo de Yauad Nader. "Primero 
-dice el traductor del Martín Fierro- pensé en traducir la obra según las normas de la poesía árabe clásica”. Optó por la métrica larga, el metro Tawil fragmentado, ${ }^{6}$ y versificó, "en traducción, no menos de 200 versos". Pero la dificultad y la "pérdida de la vitalidad del poema original" implicadas lo llevaron a abandonar ese método. Luego intentó emplear otras formas tradicionales de la poesía árabe; a saber, formas populares locales de la poesía cantada de la región de Siria, que tampoco resultaron eficaces para transmitir lo que él llamó la "realidad tangible del original" (en Hernández, 1956, p. 13). Al final optó por el verso libre, que además permitía traducir el poema verso por verso; es bien sabido que una de las normas de la poesía árabe clásica, luego adoptadas por algunos de los poetas de $\mathrm{Al} \mathrm{Nahda,} \mathrm{es} \mathrm{que} \mathrm{cada} \mathrm{verso} \mathrm{debe} \mathrm{ser} \mathrm{autónomo} \mathrm{y}$ transmitir un significado independiente.

Nader explica, y es interesante notarlo, que su decisión de emplear el verso libre en la traducción del Martín Fierro se debió a la necesidad de tener flexibilidad para preservar los esquemas de rima y métrica del original en español, hecho que se nota a lo largo de la traducción árabe del poema, especialmente en las sextillas, donde se conservan a menudo los esquemas predominantes $a b b c c d$ y $a b b c b c$ y se emplean versos cuya métrica es paralela a la del octosílabo.

Como dice Juan Villoro, el traductor a menudo se ve exiliado "a los márgenes de la tipografía, esa Siberia 'fuera' de la obra donde apunta con resignación: 'juego de palabras intraducible'" (Villoro, 2017). En el Martín Fierro de Nader hay lugar para ese exilio. Por ejemplo, en el último verso del cuarteto octosílabo del capítulo 7:
Al ver llegar la morena que no hacía caso a naides le dije con la mamúa: —«va... ca... yendo gente al baile».

(Hernández, 2000, versos 1157-1160)

${ }^{6}$ La métrica de la poesía árabe, conocida como 'urud, fue descrita y regularizada por el gramático Jalil ibn Ahmad al-Farahidi en el siglo vIII en su Kitab al-'arud. Véase Poética y métrica árabes del palestino Mahmud Sobh, publicado en 2011 por Aldebarán (Madrid). 
Una nota a pie de página explica: "Aparece en el original una frase distinta, y no le pude encontrar una traducción correcta" (en Hernández, 1956, p. 70, n. 1). En este caso, Nader inventa un nuevo verso en árabe para remplazar el original intraducible, y el último verso del cuarteto se transforma en: "y dije: / miren cuánta esclavitud hay en este lugar". Es decir, para Nader existe un juego de palabras donde "vaca" se confunde con "esclava”, y donde la animalización de la morena por la voz del protagonista alude directamente al color de la piel y a su condición histórica y social de morena-negra-esclava.

Lo que sigue es mi traducción del árabe al español del paratexto de esta curiosa edición del Martín Fierro. Para el traductor del poema, el tránsito al árabe implicó un viaje geográfico y temporal hacia la historia argentina y el lenguaje de su gente. Fue el viaje por el espacio y el tiempo el que permitió la traducción, y en él me embarco ahora tras el hallazgo de este libro en la biblioteca Daniel Cosío Villegas. Como dice Nader al final de su prólogo: "Debo decir que mi traducción no es perfecta, y espero que mi esfuerzo resulte provechoso" (en Hernández, 1956, p. 16).

\section{Referencias}

AchCAR, G. (2013). Los árabes y el Holocausto. La guerra de narrativas árabe-israelí. (Trad. Marianela Santoveña). Xalapa: Universidad Veracruzana.

BIN-MuQBIL, M. (2006). Phonetic and phonological aspects of Arabic emphatics and gutturals (tesis de doctorado). Universidad de Wisconsin-Madison.

Casas, M. E. (2015). Los gauchos de Perón. El Círculo Criollo El Rodeo, tradicionalistas y peronistas (1945-1955). Prácticas de oficio. Investigación y reflexión en ciencias sociales, 15 . Recuperado de http://ides.org.ar/wp-content/uploads/2015/09/ Mat\%C3\%ADas +Emiliano + Casas. + VER.pdf

Centro Islámico de la República Argentina. (1 de julio de 2012). El Cálamo, programa 59, 2do. bloque [archivo de video]. Recuperado de https://www.youtube.com/watch?v=DUHFOvsuBaw

HernándeZ, J. (1956). Martín Fierro. (Trad. Yauad Nader). Buenos Aires: Asociación Cultural Siria. 
Hernández, J. (2000). El gaucho Martín Fierro. Alicante: Biblioteca Virtual Miguel de Cervantes. Recuperado de http://www.cervantesvirtual.com/nd/ark:/59851/bmc639n5

HitTi, Ph. (1944). Los árabes. (Pról. Osvaldo A. Machado). Buenos Aires: Abril.

Ma qabl al-Ta'sis [Previo a la construcción]. (s.f.). Recuperado de http://www.ssnp.com/new/Saadeh/saadeh_ar.htm

Machado, O. (1935). La vida y obra de un sabio árabe: Meysed Din Al Firuzabadi, el de Chiraz. Buenos Aires: El Diario Siriolibanés.

Machado, O. (1943). Recuerdo y valoración de May. Buenos Aires: Assalam.

MACHADO, O. (1944). La historia de los godos según Ibn Jaldún. Buenos Aires: Facultad de Filosofía y Letras.

Massad, J. (2007). Desiring Arabs. Chicago: The University of Chicago Press.

Pastor de María y Campos, C. (2011). Inscribing differences: Maronites, Jews and Arabs in Mexican public culture and French imperial practices. Latin American and Caribbean Ethnic Studies, 6(2), 169-187. https://doi.org/10.1080/17442222.2011.579727

Pastor de María y Campos, C. (2014). The Mashreq unbound: Arab nationalism, Criollo nationalism and the discovery of America by the Turks. MashriqEMahjar, 2(2), 28-54. https:// doi.org/10.24847/22i2014.39

SA'ADEH, A. (s.f.). Sharh al-mabadi': Ghayat al-hizb al-sury al-Qawmy al-'iğtima'y [Explicación de los principios: el objetivo del Partido Sirio Nacionalista Social]. Recuperado de http://www.ssnp. $\mathrm{com} / \mathrm{new} / \mathrm{ssnp} / \mathrm{ar} /$ index.htm

Sовн, M. (2011). Poética y métrica árabes. Madrid: Aldebarán.

Villoro, J. (2 de febrero de 2017). El traductor. Specimen: The Babel Review of Translations. Recuperado de http://www.specimen. press/articles/el-traductor/ 


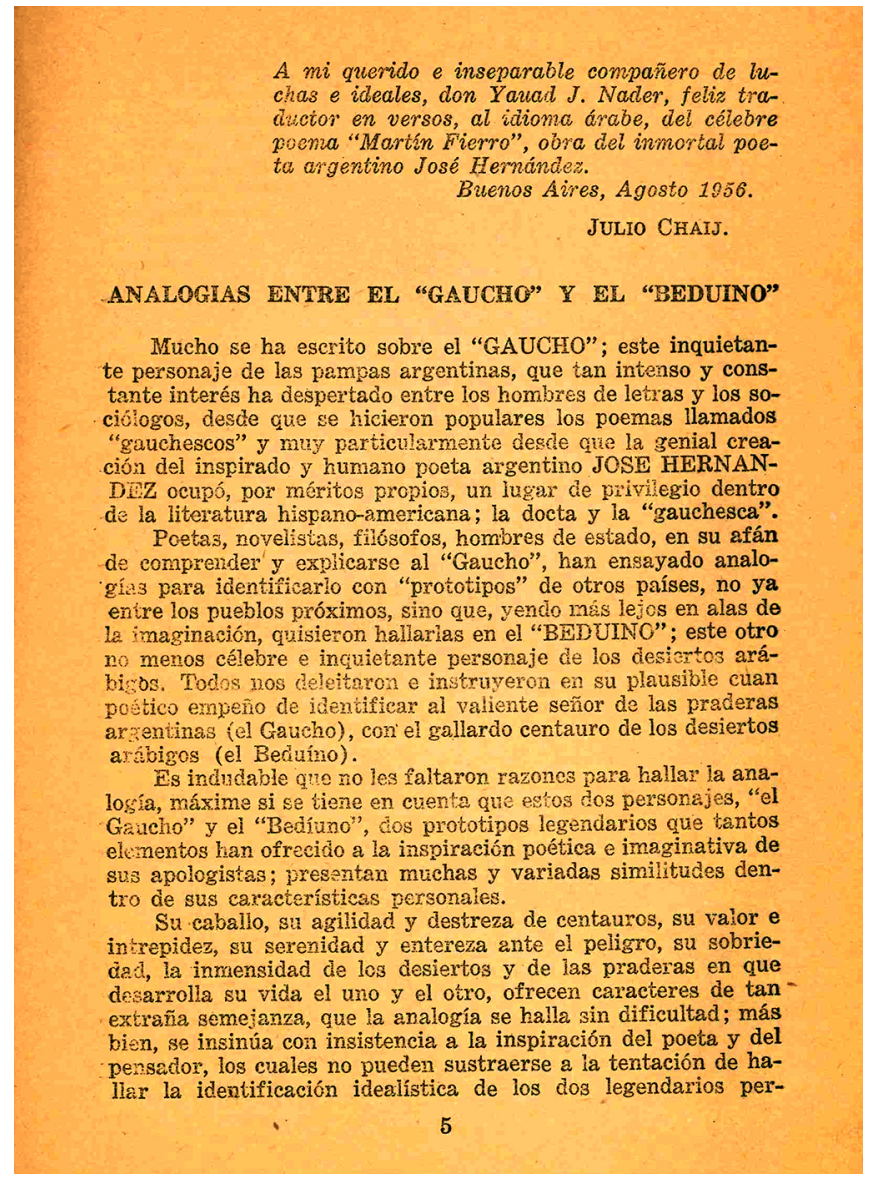

Imagen 3. "Analogías entre el 'gaucho' y el 'beduino', por Julio Chaij (apéndice, p. 5).

\section{Introducción de Osvaldo Machado (pp. 5-6)}

Se trata del conocido maestro argentino, el arabista Osvaldo Machado. Es doctor en filosofía y letras. Aprendió la lengua árabe basta dominarla; sabe hablarla como uno de los hijos de nuestra lengua, y el nivel lingüistico y de comprensión que maneja es 
igual que el de nuestros grandes letrados. Machado no se detuvo en este punto: abondó en el estudio de la filosofía árabe, en sus derivados, conceptos y deficiencias. Éste lo llevó a escribir y publicar un libro sobre el tema, un libro que comprueba la ilustración y la singularidad de su autor. Le expresé mi deseo a Machado de que fuera él quien escribiera una introducción para este poema, el Martín Fierro. Él, amablemente, consintió. La siguiente introducción fue escrita tras haber revisado él una gran parte de mi traducción. Su opinión al respecto es la de un experto y conocedor de lo que sufre un traductor al trasladar este poema famoso al árabe. A pesar de su brevedad, esta introducción constituye un indicio de la importancia y la valoración que Machado otorga a la traducción del Martín Fierro a nuestra lengua árabe (Yauad Nader).

El genio escritor, el maestro Yauad Nader, se dedicó a trasladar la historia de Martín Fierro por primera vez a la lengua árabe.

Hasta la fecha, esa historia nacional argentina había sido traducida a muchas lenguas extranjeras con excepción del árabe. Nuestro amigo letrado incurrió en esta ardua labor que involucró un enorme esfuerzo. Pues nuestra historia, el Martín Fierro, contiene palabras y expresiones que les son específicas a los habitantes de las provincias del interior argentino, algunas de ellas son locales (es decir, que expresan cosas y costumbres desconocidas por los árabes), mientras que otras no tienen ningún paralelo en absoluto en lengua árabe. Así, la traducción de esta obra requirió un esfuerzo que implicaba una investigación acerca de las condiciones y los síntomas naturales, sociales e históricos de la vida del gaucho y su entorno.

Ahora bien, podemos decir que Yauad Nader realizó un estudio exacto acerca de las costumbres de la gente del campo argentino, observando sus características, valores, modos de vivir y todo lo relacionado con sus vidas. Luego, pudo seleccionar las construcciones y las expresiones más adecuadas para representar los significados originales sin violar las reglas del árabe fusha.

En este sentido, el traductor tuvo que enfrentar abundantes dificultades y problemas, pues decidió moldear, de forma 
ágil, nuestra historia al modo de la poesía árabe en versos cuya métrica se acerca al original en español. Sí lo logró, y esa conciliación -entre contenido y forma- al traducir sólo puede ser posible cuando el traductor es competente en español y en árabe y es capaz de manejar la versificación en ambas lenguas.

Ese esfuerzo refleja la astucia, la curiosidad y la capacidad creativa y literaria de Yauad Nader. Son éstas las virtudes por las cuales es considerado como uno de los principales escritores en árabe en el mabyar.

Debemos agradecer a este buen amigo y letrado excepcional por su brillante esfuerzo y valioso servicio a ambas literaturas - la argentina y la árabe- al haber traducido la vida de un héroe argentino cuya trayectoria es muy parecida a la de Antarah ibn-Shaddad al-Absi, pues el orgullo, la caballería y el sentido poético en la vida de Martín Fierro son el reflejo de un personaje doliente cuyas intenciones y sentimientos son nobles.

Efectivamente, Yauad Nader ha satisfecho una necesidad urgente, la de publicar y circular la historia de Martín Fierro entre los intelectuales de lengua árabe. Pues éstos, por un largo tiempo, han sido privados del conocimiento de esta obra maestra de las letras argentinas.

Osvaldo Machado Buenos Aires, 1956

\section{Prólogo de Yauad Nader (pp. 11-16)}

Debido a las dificultades, los esfuerzos y las molestias que involucra la traducción del poema Martín Fierro al árabe, algunos se preguntarán sobre las causas que me llevaron a realizar tal trabajo. Otros se preguntarán acerca del provecho esperado de esta traducción y del traslado al árabe del Martín Fierro, cuyos quehaceres ocurren en lugares y tiempos muy lejanos y diferentes a los de los países árabes. Y hará muy bien el que averigüe cómo llegué a esta obra y por qué la escogí en lugar de otras. 
Respecto a las causas que me llevaron a traducirla, diría que son las mismas que llevaron a 18 traductores a traducirla a 18 lenguas. Es decir, la traduje por su belleza poética, resultado de expresar lo que se deseaba expresar; por la exactitud en las descripciones y por la armonía de sus palabras, que juntas forman las verdades ilustradas que quiso decir José Hernández en boca de su protagonista, Martín Fierro. Es indudable que la traducción dará frutos, de modo especial en nuestro país, el país de los sirios.

En esta obra, José Hernández aborda problemas que siguen vigentes en Siria: el feudalismo; el sectarismo; la arbitrariedad de los juicios injustos y los trabajos al margen de la ley; el abuso de la dignidad humana; el desprecio de la humanidad del hombre, y otros pesares que el renacer sirio nacional social quiere aliviar a través de la diligencia, la edificación de las almas y el despertar de la nación para que conozca su verdad, a dónde va y cómo debe caminar en el futuro para recuperar sus glorias pasadas.

Tantas son las similitudes entre el autor de esta historia, el poeta y pensador nacional José Hernández, y el líder Antún Sa'adeh. Hernández señaló con valentía las enfermedades y los efectos psicológicos que obstaculizan el camino de la nación. En su tiempo, advirtió también, y con toda exactitud, de las catástrofes que azotarían a la nación y que proveerían gobernantes arbitrarios y el mal gobierno de sus políticos. De igual manera, el maestro Antún Sa'adeh siempre indicó, con esa misma y rara sinceridad, mente ilustrada y pensamiento hondo y profundo, las enfermedades que le esposan las piernas a la nación y tropiezan su camino hacia el progreso, la excelencia y la gloria. Sa'adeh murió como mártir y dejó una herencia preciosa: este despertar poderoso que jura - por su honor, verdad y convicciones- que seguirá marchando por el camino que allanaron él mismo y sus mártires con la sangre casta. Este camino elevará a la nación hasta alcanzar la cumbre de la gloria, la excelencia y la dignidad. Así, volveremos a ser lo que éramos en el principio de los tiempos: un ejemplo para las demás naciones y una guía para los pueblos. 


\section{La traducción}

Corría el año de 1943, y yo trabajaba como editor en la sección árabe del diario Siriolibanés, que se publica en la capital argentina. Era el 10 de noviembre, el Día de la Tradición en Argentina, fecha que fue elegida en conmemoración del nacimiento de José Hernández por ser el primero que hizo famosa a la raza argentina, anunció su verdad y mostró su grandeza. Los periódicos y las revistas de aquel día, que se dedicaron a escribir sobre la vida de José Hernández, reproducían algunos fragmentos del Martín Fierro. Me llamó la atención la visión de Hernández acerca de los problemas de su país y las causas de su nación. Leí todo lo que se publicó aquel día. Pero no me detuve en este punto. Decidí comprarme una copia del libro. Lo leí y lo releí varias veces. Lo estudié deteniéndome en cada evento y cada aventura, en cada ternura poética y en cada ejemplo y consejo. Supe que este libro era considerado como la "Biblia criolla" - donde "criollo" quiere decir el argentino auténtico-, y que fue traducido a 18 lenguas, entre ellas japonés, rumano, inglés, ruso, yugoslavo, incluso hebreo, y todas las lenguas romances, como italiano, francés y portugués. La obra, además, fue traducida al braille y al esperanto.

Por ello pensé en la posibilidad de traducirla al árabe. Hice algunos ejercicios. Traduje, por ejemplo, los fragmentos más fáciles ("Consejos del viejo Vizcacha") y me gustó cómo sonaron en árabe. Luego hice el mismo experimento con la historia de Picardía, uno de los personajes de la historia. En 1946, cuando ya sabía más cosas sobre el gaucho, decidí por fin traducir toda la obra al árabe.

Debo decir que en aquel entonces no ignoraba ni las dificultades ni los inconvenientes que me esperaban, pues el libro contiene expresiones y modismos que le son muy extraños a la lengua árabe. Además, se mencionan cosas que no se conocen en Siria o en cualquier otro país árabe. No obstante, insistí en asumir el reto. Sabía que, como condición para la comprensión de la obra, tenía que, primero, realizar una nueva investigación acerca de los varios aspectos de la vida de la gente del campo argentino. Realicé algunos viajes a las provincias y conviví con los habitantes del campo. Le preguntaba a la gente 
sobre todo lo que me era desconocido, especialmente sobre cosas que aparecen en el Martín Fierro. Luego hice de la Biblioteca Nacional un destino de peregrinaje. La visité todos los días durante un lapso de dos meses. Hojeé sus volúmenes, copié las traducciones, dibujé las formas y grabé en mi mente las palabras y sus significados. Además, me compré tres diccionarios del habla antigua de la gente del campo y cuatro ediciones distintas del Martín Fierro, cada una con su propia introducción, notas y anotaciones en relación con la diversidad de expresiones que contiene el libro.

Primero pensé en traducir la obra según las normas de la poesía árabe clásica, pues creía que así iba a conservar el esplendor y la belleza del original. Hice el experimento: moldeaba los versos en métrica larga -Tawil- fragmentada. Así, versifiqué, en traducción, no menos de 200 versos. Pero me encontré, a menudo, obligado a modificar la métrica y la rima en la mayoría de las estrofas. Por lo tanto, comencé a considerar este tipo de rítmica como imposible de llevar a cabo, no sólo por la dificultad implicada por la longitud de la historia, sino también por la pérdida de vitalidad del poema original junto con la de las palabras originales. Sentí que varias palabras habían comenzado a perder su ternura, pues la métrica y la rima árabes, a pesar de su flexibilidad, son específicas de la lengua árabe y, al ser empleadas en un texto traducido, no necesariamente logran expresar la realidad tangible del original. Por eso decidí no apegarme a las normas de la poseía clásica árabe en mi traducción del Martín Fierro.

Luego pensé en otras convenciones nacionales de poesía, como al-záyal, al-ma'anna y al-muwashaba, y utilicé las distintas formas y maneras que conocemos en Siria. Comencé a trabajar y alcancé a traducir más de 150 versos repartidos según la división establecida en el poema original. Pero cada vez que revisaba el resultado, me veía alejado de José Hernández; es decir, entre más profundizaba en la traducción, más crecía la brecha que me separaba del autor. Tuve miedo de perder más tiempo del que ya había perdido y abandoné este segundo método.

Tras pensarlo mejor, decidí quedarme con el verso libre. Este método, creí, me permitiría conservar la estructura de las estrofas según el texto original, es decir, mantener el número 
de versos y la métrica occidental en la medida de lo posible. Así fue, y seguí trabajando hasta concluir la traducción en el año 1955.

Me gustaría aquí aludir a la generosidad de mis compañeros de la Asociación Cultural Siria, y de modo especial a su presidente fiel Jalil Cheij. Ellos siempre me apoyaron en este proyecto, insistiendo en la necesidad de que continuara este trabajo. No puedo negar los estados de desesperación y abatimiento en los que a menudo me encontré debido a las dificultades que iba confrontando. Sin embargo, esos compañeros, junto con mis hijos pequeños y mi esposa, me animaron a seguir el trabajo hasta el final.

\section{Aclaraciones}

El título original de este libro es El gaucho Martín Fierro. Martín Fierro es el nombre de un personaje, mientras que "gaucho" es la deformación de la palabra guacho, o sea, que no tiene padres. Había mucha gente de este tipo durante los primeros momentos de la formación de la nación argentina: una mezcla de emigrantes que poco a poco comenzaron a ambientarse en la tierra y a construir comunidades que luego, con el tiempo, comenzaron a formar la nación. El gaucho fue conocido por su capacidad de confrontar las aventuras y las dificultades, por sus andanzas de un lugar a otro, y por su generosidad, sacrificio, valentía y valor. Cuando apareció la familia y comenzó a desarrollarse de forma natural, la palabra "gaucho" denominó, entre otras, estas características ya mencionadas. Por ejemplo, la gente comenzó a decir "esta persona es como un gaucho", o sea, que esta persona es valiente, etcétera.

En el libro aparece también la palabra “indio". Para evitar una confusión con India, explicamos lo siguiente: según el mito del descubrimiento de América por Cristóbal Colón, el almirante navegó desde los puertos de España en búsqueda de India. Colón se perdió en el mar, hasta que un día llegó a una tierra donde vio personas. Pensó que era India y, por ende, llamó a esas personas con el nombre de "indios". Pero esa tierra a la que llegó Colón era nada más que América, y esas personas eran los 
viejos habitantes del continente. Estaban semidesnudos. A pesar de que más tarde fue evidente para Colón que la tierra a la que había llegado no era India, se seguía la costumbre de llamar a aquellas personas con el nombre de "indios".

\section{Las trampas de la traducción}

Todos los traductores deben acudir a la trampa, es decir, a ambientar la palabra al idioma de destino mientras intentamos, dentro de lo posible, conservar el significado de la palabra según el idioma de origen. En la mayoría de los casos, nosotros los traductores sí lo logramos. Sin embargo, hay veces en que fracasamos. El "fracaso" aquí no es total, y tampoco viene de una mala intención. El traductor, a pesar de todo su esfuerzo intelectual y de memoria, y a pesar de todas las trampas que emplea para transmitir los significados, puede tropezar. Al traducir poesía, esos tropiezos se vuelven más comunes. $\mathrm{La}$ poesía, pues, es el género más difícil para la traducción. El poeta, cuando versifica, no piensa en la posibilidad de que habrá, en el futuro, una persona que traducirá sus versos. Es por eso natural que el poeta subordine los significados a su imaginación, y el traductor, por ende, está obligado a crear una imaginación nueva y volar en nuevos ambientes para encontrar las palabras que armonicen con la imaginación del poeta; que expresen los significados que quiere expresar el poeta.

Esa dificultad alcanza su pico cuando uno traduce de los idiomas romances al árabe, aún más cuando se trata de poesía. Tanto en español como en francés, italiano y portugués, se versifica según métricas específicas, donde cada verso, en la mayoría de los casos, carece de autonomía en el significado. Es decir, a menudo nos encontramos con una cierta idea, expresada a lo largo del primer, segundo, tercero, cuarto y hasta el sexto verso, lo que ocurre a menudo en el caso del Martín Fierro. El traductor puede lograr transmitir el significado de seis versos escritos en español en uno o dos versos escritos en árabe. Sin embargo, en este caso la traducción no será completa, pues el poema contiene palabras tiernas, exactas, lindas y maravillosas cuyo efecto debe conservarse. En este sentido, aquí la trampa 
juega un papel importante en la creación no sólo de imágenes fieles al origen, sino también de los ritmos de las palabras y la musicalidad de las rimas.

La dificultad no acaba aquí. Es común que lo que quiere decir el poeta no es el significado aparente de la palabra. Hay muchos significados ocultos en la poesía. Por ejemplo, el poeta puede decir "camello", mientras que lo que está diciendo es "montaña"; puede decir "pan”, pero lo que está diciendo es "vida" y "vivir"; dice "piedra", pero quiere decir "fuerza"; dice "suelo" para hablar de la humildad; y dice "cielo" para hablar de la elevación, etc. El Martín Fierro habla el lenguaje de las gentes del campo y reproduce los dichos que circulan entre ellas. Esos dichos están llenos de diferencias entre lo que se dice y los significados ocultos. Por eso decidí que la mejor manera de traducir el poema sería estrofa por estrofa, manteniendo en cada una el número de versos de origen. Además, intenté emplear los esquemas de rima que aparecen en el original para así conservar el ritmo poético.

Sin embargo, debo decir que mi traducción no es perfecta, y espero que mi esfuerzo resulte provechoso. 
